\title{
Identification and characterization of rod-derived cone viability factor
}

\author{
Thierry Léveillard ${ }^{1,5}$, Saddek Mohand-Saïd ${ }^{1}$, Olivier Lorentz ${ }^{1}$, David Hicks ${ }^{1}$, Anne-Claire Fintz ${ }^{1}$, \\ Emmanuelle Clérin ${ }^{1}$, Manuel Simonutti ${ }^{1}$, Valérie Forster ${ }^{1}$, Nükhet Cavusoglu ${ }^{1}$, Frédéric Chalmel ${ }^{2}$, Pascal Dollé ${ }^{2}$, \\ Olivier Poch ${ }^{2}$, George Lambrou ${ }^{3} \&$ José-Alain Sahel ${ }^{1,4,5}$
}

\begin{abstract}
Retinitis pigmentosa is an untreatable, inherited retinal disease that leads to blindness. The disease initiates with the loss of night vision due to rod photoreceptor degeneration, followed by irreversible, progressive loss of cone photoreceptor ${ }^{1-3}$. Cone loss is responsible for the main visual handicap, as cones are essential for day and high-acuity vision ${ }^{4}$. Their loss is indirect, as most genes associated with retinitis pigmentosa are not expressed by these cells. We previously showed that factors secreted from rods are essential for cone viability ${ }^{5-8}$. Here we identified one such trophic factor by expression cloning and named it rod-derived cone viability factor (RdCVF). RdCVF is a truncated thioredoxin-like protein specifically expressed by photoreceptors. The identification of this protein offers new treatment possibilities for retinitis pigmentosa.
\end{abstract}

We used a viability assay based on cone-enriched primary cultures from chicken embryos ${ }^{9}$ for expression cloning. Unlike those of mammals, bird retinas are cone-dominated. Cones represent $60-80 \%$ of the total population in cultured cells ${ }^{8}$. Once cultured, these cells degenerate over a few days, but adding conditioned medium from wild-type mouse retinal explants delays this $\operatorname{loss}^{8}$. We carried out a screen to isolate factors that could support cone survival.

We constructed a cDNA expression library from neural retinas of 5 -week-old wild-type mice and we purified plasmid DNA from pools of 100 individual clones and used them to transfect COS- 1 cells. We added conditioned medium from transfected COS cells to chicken retinal cultures seeded in 96-well plates. After $7 \mathrm{~d}$ of culture, we carried out an automated viability assay and we screened 2,100 pools, corresponding to 210,000 individual clones. Pool 939 contained twice as many living cells as the negative controls (Fig. 1). We isolated clone 939.09.08 by limiting dilution and found that it contained a 502-bp insert with an open reading frame encoding a putative polypeptide of 109 amino acids. We named this protein rod-derived cone viability factor (RdCVF, international patent no. PCT/EP 02/03810; Supplementary Fig. 1 online).
We then expressed and purified RdCVF as a fusion protein with gluthatione-S-transferase (GST; Fig. 2a). We incubated cone-enriched cultures with increasing amounts of GST-RdCVF or GST alone. Adding $10 \mu \mathrm{g} \mathrm{ml}^{-1}$ of purified GST-RdCVF doubled the number of living cells per plate. The rescue activity of this factor increased with higher protein concentration (Fig. 2b).

We next cultured retinal explants from 5-week-old $r d 1$ mice (lacking rods) for $7 \mathrm{~d}$ with COS cells transfected with cDNA encoding RdCVF (from clone 939.09.08). We labeled cone cells with cone-specific peanut agglutinin (PNA) and counted them using stereological methods ${ }^{7}$. The number of cones per field was higher in retinal explants incubated with cells transfected with RdCVF than in controls (Fig. 2c). The amplitude of the rescue effect was $40 \%$ when comparing the number of cones lost during the 1-week period, a range of efficacy similar to that observed when wild-type retinas were used as a source of RdCVF activity ${ }^{7}$. RdCVF was thus able to slow cone degeneration in both chick and mouse models ${ }^{8}$. We cultured retinal explants from 10-d-old $r d 1$ mice (with rods) for $7 \mathrm{~d}$ with COS cells transfected with cDNA encoding RdCVF and measured the thickness of the outer retina. We observed no statistically significant differences in the thickness of the outer retina between mice transfected with RdCVF and controls, indicating that the protective effects of RdCVF might not extend to degenerating rods (Fig. 2d).

We next tested the ability of RdCVF antibodies to block endogenous activity. We prepared conditioned medium from retinal explants of 5-week-old wild-type mice and immunodepleted them with antibodies to RdCVF or control antibodies. We incubated retinal explants of 5-week-old $r d 1$ mice (lacking rods) for $7 \mathrm{~d}$ with conditioned medium and then labeled and counted the cones. The number of cones was higher when $r d 1$ explants were incubated with conditioned medium preincubated with control polyclonal antibodies than when they were incubated with medium alone (Fig. 2e). The conditioned medium did not stimulate cone survival in $r d 1$ explants when RdCVF was specifically removed by immunodepletion. These results indicate that RdCVF is required for cone rescue in cultured explants.

${ }^{1}$ Laboratoire de Physiopathologie Cellulaire et Moléculaire et de la Rétine, Inserm U592, Université Pierre et Marie Curie, Hôpital St-Antoine, 184 rue du Faubourg St-Antoine, 75571, Paris cedex 12, France. ${ }^{2}$ Institut de Génétique et de Biologie Moléculaire et Cellulaire, 1 rue Laurent Fries, 67404 IIlkirch, France. ${ }^{3}$ Novartis Pharma AG Ophthalmology Research WKL-127.1.04 CH-4002 Basel, Switzerland. ${ }^{4}$ Institute of Ophthalmology, University College of London, UK. ${ }^{5}$ These authors contributed equally to this work. Correspondence should be addressed to T.L. (leveilla@st-antoine.inserm.fr). 


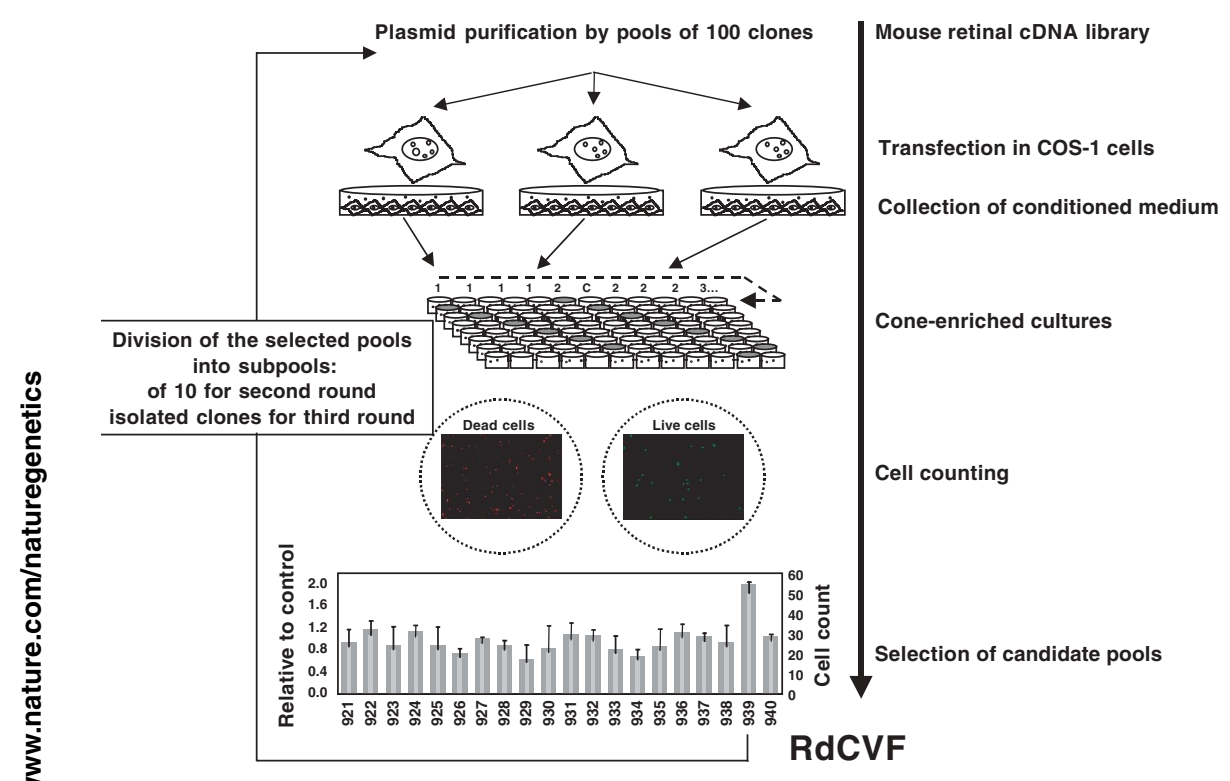

Figure 1 Schematic representation of the expression cloning strategy. Cell count indicates the number of live cells. 'Relative to control' is the ratio of live cells from the indicated clone to live cells in wells transfected with pcDNA3.

When antibodies to RdCVF were injected into the subretinal space of the wild-type mouse, the number of cones decreased $7 \mathrm{~d}$ after the injection, as compared with mice similarly injected with control antibodies (data not shown), but the difference was not statistically significant. Complete blocking of RdCVF signaling in vivo requires gene inactivation by homologous recombination.

To assess the effect of RdCVF in vivo, we injected $1 \mu \mathrm{l}(100 \mathrm{ng})$ of purified GST-RdCVF in the subretinal space of 35-d-old $r d 1$ mice and repeated the injection $7 \mathrm{~d}$ later. We killed the mice at 7 weeks of age (Fig. 2f). The average number of cones per $\mathrm{mm}^{2}$ was higher in mice injected with the RdCVF fusion protein $(4,500)$ than in mice injected with either GST alone $(3,800)$ or with phosphate-buffered saline (PBS; 3,500). Therefore, injection of RdCVF can prevent $40 \%$ of cones from degenerating in the $r d 1$ mouse over a period of 2 weeks.

Northern-blot analysis detected two distinct RdCVF mRNAs of 2.3 and $2.7 \mathrm{~kb}$ in only the retina and not in any other tissue tested (Fig. 3a). The pattern of RdCVF mRNA expression shown by real-time RT-PCR matched that of rhodopsin, largely increasing during maturation of photoreceptors in the wild-type mouse. In the $r d 1$ mouse, however, rod degeneration, as indicated by decreased rhodopsin mRNA levels, was accompanied by a marked decrease in RdCVF expression (Fig. 3b). The two RdCVF mRNAs are probably a result of alternative splicing. When tested by real-time RT-PCR, the most abundant mRNA encoded the factor that we isolated (Fig. 3c). The level of expression of RdCVF in the whole retina and in the photoreceptor layer (isolated by sectioning the mouse retina with a vibratome ${ }^{10}$ ) were similar. This suggests that RdCVF expression is mainly restricted to the outer nuclear layer containing the rods and cones (Fig. 3d). RdCVF is also expressed in cultures of pure photoreceptors (Fig. 3e).

Polyclonal antibodies raised against the $\mathrm{N}$-terminal and C-terminal regions of the RdCVF sequence (RdCVF-N and RdCVF-C, respectively) detected the same two bands (17 and $34 \mathrm{kDa}$, Fig. 4a). In vitro, translated RdCVF consists only of a $17-\mathrm{kDa}$ band, possibly resulting a

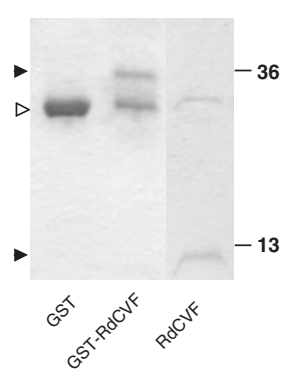

C

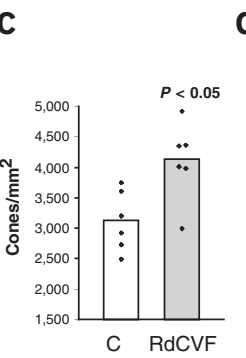

d

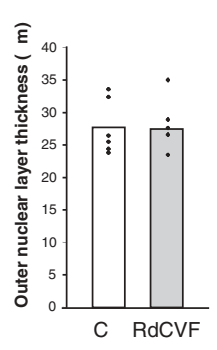

b

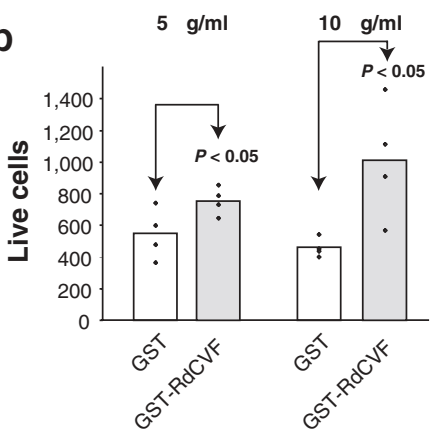

e

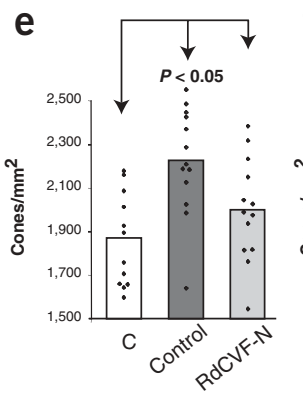

f

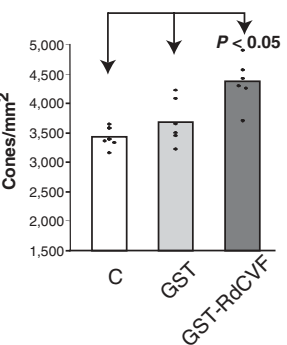

Figure 2 Viability activity of RdCVF. (a) Gel analysis of purified GST (lane 1), GST-RdCVF (lane 2) and thrombin-cleaved and purified RdCVF (lane 3). Arrows on the left indicate the RdCVF proteins; the open arrowhead indicates GST. Molecular weight markers $(\mathrm{kDa})$ are shown on the right. (b) Activity of GST and GST-RdCVF in chicken cone-enriched cultures. The assay represents the sum of eight independent experiments. (c) Effect of cDNA encoding RdCVF transfected into COS- 1 cells on cone viability in $r d 1$ mouse retinal explants. C, pcDNA3; RdCVF, pcDNA-RdCVF. (d) Effect of cDNA encoding RdCVF transfected into COS- 1 cells on rod viability in $r d 1$ mouse retinal explants. C, pcDNA3; RdCVF, pcDNARdCVF. (e) Immunodepletion with antibodies to RdCVF-N. C, chemically defined medium; control, conditioned medium from wild-type retinal explants after immunodepletion with control antibodies; RdCVF-N, conditioned medium from wild-type retinal explants after immunodepletion with RdCVF antibodies. (f) Subretinal injection of $1 \mu \mathrm{l}$ of PBS (C), GST (100 ng) and GST-RdCVF (100 ng). 
Figure 3 Expression of RdCVF mRNA. (a) Northern-blot analysis of RdCVF mRNA prepared from different adult mouse tissues. WT, wild-type. (b) Real-time RT-PCR analysis quantifying RdCVF levels in wild-type (WT) and $r d 1$ retinas at postnatal day (P) 8, P15 and P35. The results are given relative to the level expressed in 35-d-old $r d 1$ mice. (c) Real-time RT-PCR analysis quantifying RdCVF and RdCVFL mRNA. The results are given relative to the level expressed in 35-d-old $r d 1$ mice. (d) RT-PCR products of RdCVF mRNA amplification from wild-type (WT) retina and isolated photoreceptors (PR). (e) RdCVF mRNA expression: C, negative control; Retina, retina from 5-week-old wild-type mouse; PR, pure culture of photoreceptors; Mü, Müller glial cells.

from post-translational modifications of the $12-\mathrm{kDa}$ polypeptide (Fig. 2a). The amount of RdCVF protein was similar in retinal extracts from normal and mutant strains at 1 week of age, before rod degeneration (Fig. 4b). The levels of both bands were not substantially modified between 2 and 5 weeks of age in the wild-type mouse. In contrast, the amounts of RdCVF decreased from 2 weeks onwards in the $r d 1$ mouse, in correlation with the kinetics of rod degeneration $^{11}$. We detected the $34-\mathrm{kDa}$ form of RdCVF in the conditioned medium produced from wild-type retinal explants (Fig. 4c). Additional polyclonal antibodies were raised against a peptide specific to RdCVFL, the longer form of the protein. When transfected into COS cells, cDNA encoding RdCVFL was specifically detected by antibodies to RdCVFL and RdCVF-C, whereas the short form of RdCVF was specifically detected by antibodies to RdCVF-C (Fig. 4d). This indicates that the $34-\mathrm{kDa}$ band detected in retinal extracts and conditioned medium corresponds to the long form of RdCVF. Analysis of conditioned medium compared with cell lysate indicated that both forms of the protein were secreted by transfected COS cells.

We carried out immunohistochemical analysis of retinal sections from 5-week-old mice with antibodies to both RdCVF-N and RdCVF-C (Fig. 5). We observed specific staining on photoreceptor outer segments and the interphotoreceptor matrix (Fig. 5c,g). Staining was particularly intense in discrete structures within the subretinal space, colocalizing with the binding of PNA, a marker of cone matrix sheaths (Fig. 5a,d,e,h). We detected no expression in retinal sections from 5 -week-old $r d 1$ mice (data not shown). The preferential localization of RdCVF in the cone extracellular matrix suggests that a cell surface RdCVF receptor is present on target cells (Fig. 5c,g). As expected, RdCVF mRNA was prominently detected by in situ hybridization in the outer nuclear layer of the wild-type retina (Fig. 5i). The observed labeling is consistent with RdCVF being

Figure 4 Expression of RdCVF protein. (a) Western blotting of retinal extracts from wild-type mice. In vitro translated RdCVF (Tx-tl) and retinal extracts probed with antibodies to RdCVF-N and RdCVF-C are shown. Molecular weight markers $(\mathrm{kDa})$ are shown on the right. (b) Western blotting using polyclonal antibodies to RdCVF-N of retinal extracts from wild-type (first four lanes) and $r d 1$ mice (second four lanes) at 8, 15, 21 and $35 \mathrm{~d}$ after birth. The last lane shows wild-type whole brain (Br) $35 \mathrm{~d}$ after birth. Molecular weight markers $(\mathrm{kDa})$ are shown on the right. (c) Western-blot analysis with antibodies to RdCVF-N of wild-type retinal explants (WT Ext) and conditioned medium (CM) from wild-type (WT) and $r d 1$ mice $35 \mathrm{~d}$ after birth. Molecular weight markers $(\mathrm{kDa})$ are shown on the left. (d) COS-1 cell extracts after transfection of cDNA encoding the open reading frames of RdCVF and RdCVFL. The control corresponds to the empty vector. The extracts were probed by western blotting with antibodies specific to RdCVF$\mathrm{N}$ and RdCVFL. Molecular weight markers ( $\mathrm{kDa}$ ) are shown on the right.

a

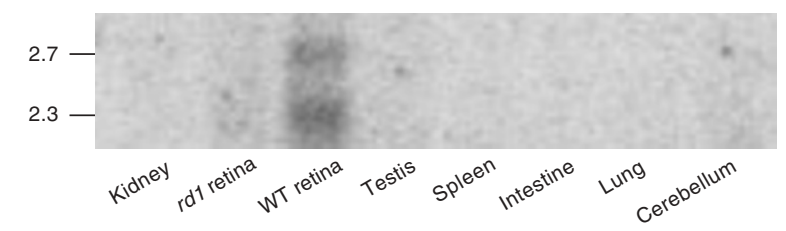

b

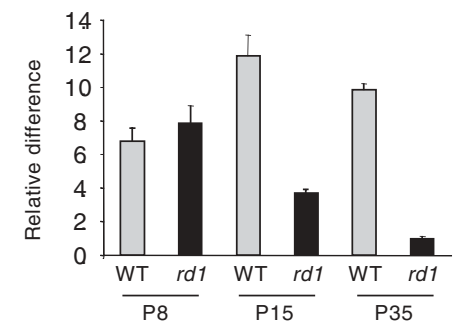

C

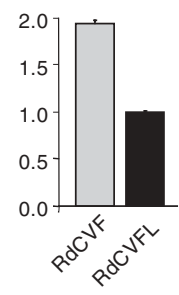

d

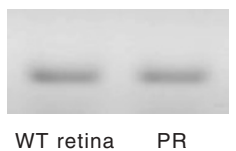

e

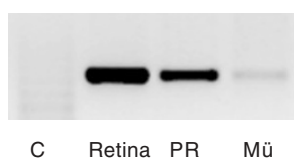

expressed by all rod photoreceptors. We used a Pax6 probe in the same experiment as a specificity control (Fig. $\mathbf{5 j}$ ).

This study provides a biochemical basis for the previously described paracrine interaction between rod and cone photoreceptors that seems to have a key role in maintaining cone cell viability ${ }^{7}$. Previous studies suggested that Müller glial cells mediated photoreceptor rescue ${ }^{12}$. The finding that RdCVF is expressed predominantly by photoreceptors implies a new mode of trophic interactions. The systematic expression cloning strategy that we used led to the identification of a protein from a family that has not previously been documented to include trophic factors.

RdCVF has 33\% similarity with thioredoxin ${ }^{13}$ (Supplementary Fig. 1 online). The $\mathrm{C}$ terminus of RdCVF interrupts the thioredoxin motif and, unlike other members of the thioredoxin family ${ }^{13}$, recombinant RdCVF did not have detectable oxidoreductase activity ${ }^{14}$ (data not shown). RdCVF is thus a truncated thioredoxin-like protein ${ }^{13}$. The founding member of this family, Trx-1, has also been isolated as the adult $\mathrm{T}$-cell leukemia-derived factor ${ }^{15}$, secreted by cells by a mechanism that does not involve a signal peptide sequence; this signal is also absent

a

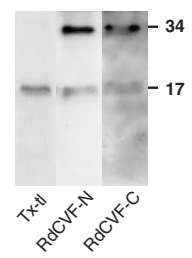

C

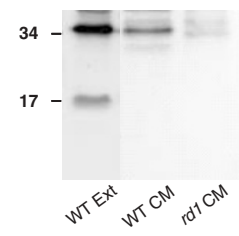

b

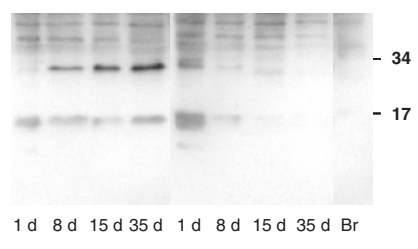

RdCVF-N

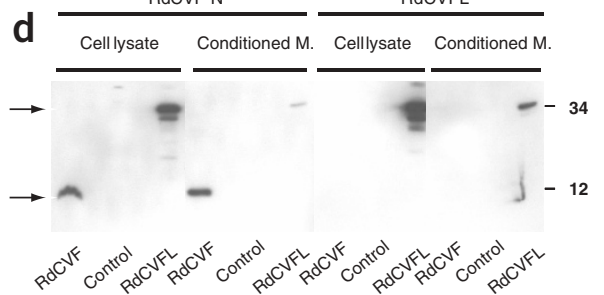

d

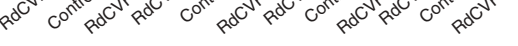




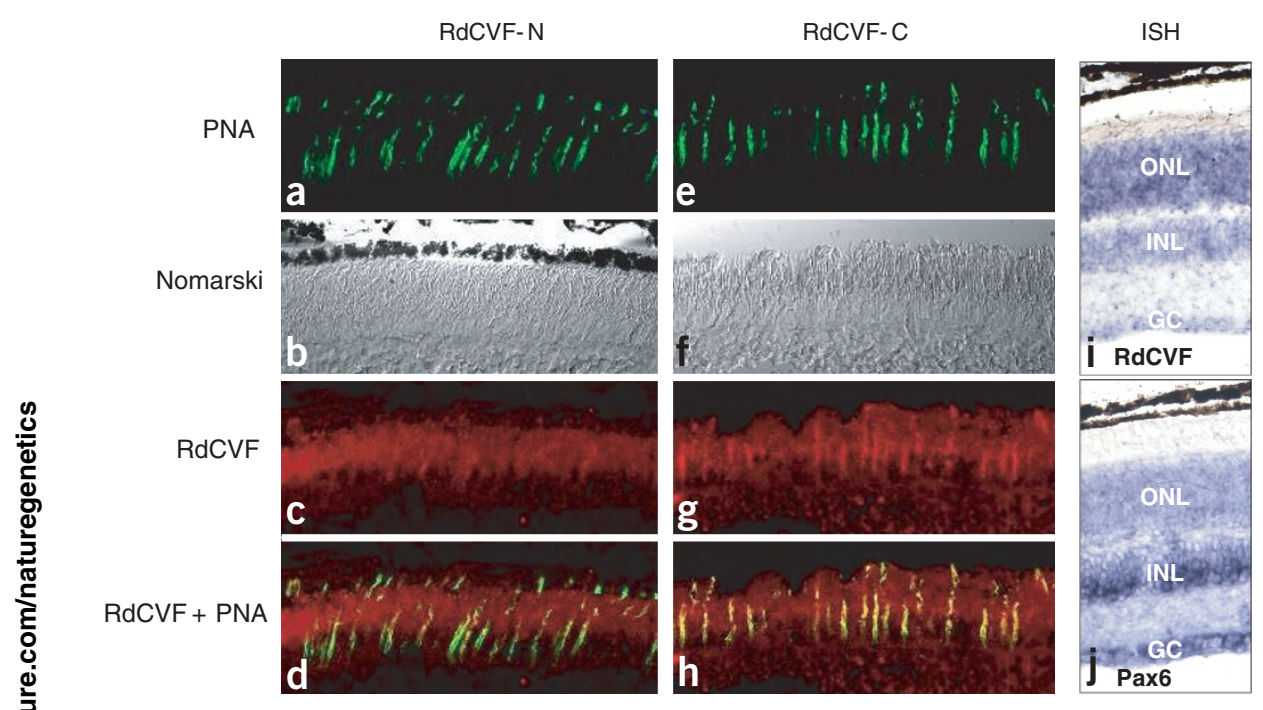

Figure 5 RdCVF localization in 35-d-old wild-type mouse retina. (a,e) PNA labeling. (b,f) Nomarski image of immunolabeled sections. $(\mathbf{c}, \mathbf{g})$ Staining with an affinity-purified polyclonal antibody to RdCVF-N (c) and RdCVF-C (g). (d,h) Merge of PNA and RdCVF staining. (i,j) In situ hybridization (ISH) of RdCVF (i) and Pax6 (j) riboprobes on adjacent sections of 5-week-old wild-type mouse retina. GC, ganglion cells; INL, inner nuclear layer; ONL, outer nuclear layer.

in $\mathrm{RdCVF}^{16}$. An alternatively spliced form of RdCVF mRNA results in a longer protein with a C-terminal extension and could have oxidoreductase activity (Supplementary Fig. 1 online). RdCVF might be a new example of a bifunctional protein ${ }^{17}$, with one extracellular form involved in cone viability and the other (with an extended C-terminal sequence) having oxidoreductase activity.

\section{METHODS}

Mice. Care and handling of mice in these studies conformed to the Association for Research on Vision and Ophthalmology Resolution on the use of animals in research.

Expression cloning. We constructed a directional cDNA plasmid library using the neural retina mRNAs of 35-d-old wild-type (C57BL/6@N) mice. We purified pools of 100 plasmids and used them to transfect COS-1 cells ${ }^{18}$. We removed the serum and, $48 \mathrm{~h}$ after transfection, collected the conditioned medium from COS-transfected cells and incubated it for $7 \mathrm{~d}$ with primary retina cultures from chicken embryos ${ }^{9}$ (stage 29) in 96-well black tissue-culture plates (Corning). We included 14 negative control wells (conditioned medium from COS cells transfected with pcDNA3 vector alone). We used a live/dead assay (Molecular Probes) to monitor cell viability. For acquisition and cell counting, we developed an algorithm based on the Metamorph software (Universal Imaging Corporation). We read plates under an inverted fluorescence microscope (TE 200, Nikon) equipped with a mercury epifluorescent lamp with two excitation filters ( 485 and $520 \mathrm{~nm}$ ), two emission filters (520 and $635 \mathrm{~nm})$, a 10× objective, a computer-driven motorized scanning stage (Märzhäuser) and a CCD camera (Fig. 1). For the first round of screening, we compared numbers of live cells with the mean number of live cells in the negative controls. For the second and third rounds, the screening for sub-pools included positive controls (conditioned medium from wild-type retina).

We tested RdCVF activity on cones of $r d 1$ retinal explants by transfecting COS cells with pcDNA-RdCVF or the empty vector. We incubated COS-transfected cells for $72 \mathrm{~h}$ in coculture chambers containing retinal explants from 35d-old $r d 1$ mice. We repeated the transfection and coculture steps for an additional $72 \mathrm{~h}$. We tested RdCVF activity on rods of 10-d-old $r d 1$ mice using the same experimental protocol. We assessed the number of rods by measuring the thickness of the outer nuclear layer on four different areas spanning the total width of the explants, one central and one peripheral region on each side of the optic nerve. For in vivo injections, we injected $100 \mathrm{ng}$ of purified GST-RdCVF and unfused GST into the subretinal space of 35-d-old $r d 1$ mice. We labeled cones with PNA $\left(50 \mu \mathrm{g} \mathrm{ml}^{-1}\right)$ and counted them using a stereological method ${ }^{7}$.

DNA sequencing and data mining. We sequenced isolated cDNAs using the T7 primer and used the DNA sequences to screen databases using BLAST ${ }^{19}$.
Northern blotting and real-time RT-PCR. For northern-blot analysis we used $2 \mu \mathrm{g}$ of poly $(\mathrm{A})^{+}$mRNA. We produced cDNAs by random priming and normalized them to glucose-6-phosphate dehydrogenase mRNA. We amplified first-strand cDNA $(0.2 \mu \mathrm{l})$ in triplicate using $2 \mu \mathrm{M}$ of the specific primers for RdCVF and for the long form on a lightcycler (Roche). Primer sequences are available on request. Results are expressed as difference relative to the lowest expressing sample.

Recombinant protein production and purification. We cloned the open reading frame of RdCVF into pGex2TK (Amersham), produced the fusion protein at $30^{\circ} \mathrm{C}$ in Escherichia coli BL21 pLysS (Promega) and purified it using standard procedures.

In vitro translation. We incubated pcDNA-RdCVF $(2 \mu \mathrm{g})$ with TNT reticulocyte lysate (Promega) and ${ }^{35} \mathrm{~S}$ methionine according to standard procedures.

Polyclonal antibody production and purification. We prepared rabbit polyclonal antibodies with the following peptides: for RdCVF-N, IRNNSDQDEVETEAELSRRLEN; for RdCVF-C, SQDPTEEQQDLFLRDMPE; and for RdCVFL, RKYRVDRDVGRERGRNGRD. We purified immunoglobulins from immune serum and affinity-purified specific antibodies onto immobilized epitopes. We produced polyclonal antibodies against blue cone pigment using the peptide CGPDWYTVGTKYRSE and purified them as described above.

Western blotting, immunohistochemistry, in situ hybridization and immunodepletion. For western blotting, we resolved $40 \mu \mathrm{g}$ of whole-cell extract from neural retina or conditioned medium from mouse retinal explants by $15 \%$ SDS-PAGE and transferred it onto nitrocellulose. We saturated the membrane and incubated it for $3 \mathrm{~h}$ at $20^{\circ} \mathrm{C}$ with affinity-purified polyclonal antibodies to $\operatorname{RdCVF}\left(0.1 \mu \mathrm{g} \mathrm{ml}^{-1}\right)$.

For immunohistochemistry, we dissected eyes from 5-week-old wild-type mice (C57BL/6@N), fixed them in $4 \%$ paraformaldehyde in PBS at $4{ }^{\circ} \mathrm{C}$ for $12 \mathrm{~h}$, cryoprotected them and embedded them in OCT. We cut serial cryostat sections $(10 \mu \mathrm{m})$. We rinsed coverslips and slides in PBS and blocked them with blocking buffer (PBS containing $0.1 \%$ Tween 20 and $0.1 \%$ bovine serum albu$\mathrm{min}$ ) for $30 \mathrm{~min}$ and then incubated them with the diluted RdCVF antibodies $\left(2 \mu \mathrm{g} \mathrm{ml}^{-1}\right)$ overnight at $4{ }^{\circ} \mathrm{C}$. We rinsed the slides in PBS (ten washes over a total of $1 \mathrm{~h}$ ) and incubated them with antibodies to goat IgG conjugated to AlexaFluor 488 (Molecular Probes). Finally, we washed slides extensively in PBS and mounted them in PermaSave. We observed cellular distribution using a confocal laser scanning microscopy (Zeiss LSM 510 v2.5) scanning device mounted on a Zeiss Axiovert 100 inverted microscope.

For immunodepletion, we maintained retinal explants from 35-d-old wildtype (C57BL/6@N) neural retinas for $48 \mathrm{~h}$ at $37^{\circ} \mathrm{C}$ in a $5 \% \mathrm{CO}_{2}$ atmosphere in a chemically defined medium ${ }^{9}$ ( 1 explant per $0.75 \mathrm{ml}$ ). We covalently coupled 
affinity-purified polyclonal antibodies $(2.5 \mathrm{mg})$ to Sepharose beads using protein A. We incubated $6 \mathrm{ml}$ of conditioned medium overnight at $4{ }^{\circ} \mathrm{C}$ with immobilized polyclonal antibodies, control antibodies raised against the blue cone visual pigment and antibodies to RdCVF-N. We incubated the retinal explants prepared from 35-d-old mice over a period of $7 \mathrm{~d}$ with conditioned medium. We labeled cones with PNA. We mounted labeled explants on glass slides and placed them on a computer-driven motorized scanning stage (Märzhäuser). We counted cone cells using a specially designed procedure and Metamorph software (Universal Imaging Corporation). We generated a composite image of the explants to calculate the explant area. Within this area, we acquired five images at the focal depth for $40 \times$ magnification after excitation at $520 \mathrm{~nm}$ and emission at $635 \mathrm{~nm}$ with automatic exposure times. We deconvoluted these stacks of images to count cone numbers in the depth of the explants. The automation gives a density of cones that is reproducibly lower by a factor of 2 than the density obtained by stereological methods, due to the filtering of the images. We carried out in situ hybridization on cryosections of eyes from 5-week-old wild-type mice (C57BL/6@N) essentially as described ${ }^{20}$, using riboprobes labeled with dixoxigenin-UTP (Roche).

Enzymatic assay. We carried out enzymatic assays as described ${ }^{14}$. We monitored the enzymatic activity of E. coli thioredoxin as a positive control.

Statistical analysis. Statistical analysis of the results is based on different nonparametric tests: Mann-Whitney $t$-test for paired comparisons and Bonferroni method for multiple comparisons ${ }^{21}$. We used variance analysis (ANOVA) and Fischer $t$-test to analyze the dose-response effect.

URLs. The Retinal Information Network is available at http://www.sph.uth. tmc.edu/Retnet/.

Note: Supplementary information is available on the Nature Genetics website.

\section{ACKNOWLEDGMENTS}

We thank A. Gluck, J. Ravey, D. Thiersé, M. Simonutti, V. Forster, N. Hanotteau, G. Millet-Puel, G. Lucchi, P. Oberlin and G. Tarlet for technical assistance; A. Dolemeyer, C. Grolleau, E. Scherbeck and P.-Y. Boelle for help; P. Chambon for support; and E. Borelli, O. Goureau, V. Heidinger, A. Triller and D. Zack for critical reading of the manuscript. This work was financed by Novartis, Inserm, Ministère de la Recherche, the Association Française contre les Myopathies, the Fédération des Aveugles de France, Retina France, Foundation Fighting Blindness (USA), IPSEN Foundation and the European Community (PRO-AGE-RET program).

\section{COMPETING INTERESTS STATEMENT}

The authors declare competing financial interests (see the Nature Genetics website for details).
Received 6 November 2003; accepted 17 May 2004

Published online at http://www.nature.com/naturegenetics/

1. Rosenfeld, P.J. et al. A null mutation in the rhodopsin gene causes rod photorecepto dysfunction and autosomal recessive retinitis pigmentosa. Nat. Genet. 1, 209-213 (1992).

2. McLaughlin, M.E. Sandberg, M.A., Berson, E.L \& Dryja, TP. Recessive mutations in the gene encoding the beta-subunit of rod phosphodiesterase in patients with retinitis pigmentosa. Nat. Genet. 4, 130-134 (1993).

3. Kajiwara, K., Berson, E.L. \& Dryja, T.P. Digenic retinitis pigmentosa due to mutations at the unlinked peripherin/RDS and ROM1 loci. Science 264, 1604-1608 (1994).

4. Dowling, J.E. The retina: an approachable part of the brain. in Retinal Cells and Processing (Harvard University Press, Cambridge, Massachusetts, 1987).

5. Mohand-Saïd, S. et al. Photoreceptor transplants increase host cone survival in the retinal degeneration (rd) mouse. Ophthalmic Res. 29, 290-297 (1997).

6. Mohand-Saïd, S., Hicks, D., Léveillard, T., Dreyfus, H. \& Sahel, J. Selective transplantation of rods delays cone loss in a retinitis pigmentosa model. Arch. Ophthalmol. 118, 807-811 (2000).

7. Mohand-Saïd, S. et al. Normal rod photoreceptors increase cone survival in the retinal degeneration (rd) mouse. Proc. Natl. Acad. Sci. USA 95, 8357-8362 (1998).

8. Fintz, A.C. et al. Partial characterization of retina-derived cone neuroprotection in two culture models of photoreceptor degeneration. Invest. Ophthalmol. Vis. Sci. 44, 818-825 (2003)

9. Adler, R. \& Hatlee, M. Plasticity and differentiation of embryonic retinal cells after terminal mitosis. Science 243, 391-393 (1989).

10. Fontaine, V., Kinkl, N., Sahel, J., Dreyfus, H. \& Hicks, D. Survival of purified rat photoreceptors in vitro is stimulated directly by fibroblast growth factor-2. J. Neurosci. 18, 9662-9672 (1998)

11. Carter-Dawson, L.D., La Vail, M.M. \& Sidman, R.L. Differential effect of the rd mutation on rods and cones in the mouse retina. Invest. Ophthalmol. Vis. Sci. 17, 489-498 (1978).

12. Zack, D. Neurotrophic rescue of photoreceptors: are Müller cells the mediator of survival? Neuron 26, 285-286 (2000).

13. Arner, E.S. \& Holmgren, A. Physiological functions of thioredoxin and thioredoxin reductase. Eur. J. Biochem. 267, 6102-6109 (2000).

14. Holmgren, A. Thioredoxin catalyzes the reduction of insulin disulfides by dithiothreitol and dihydrolipoamide. J. Biol. Chem. 254, 9627-9632 (1979).

15. Wakasugi, N. et al. Adult T-cell leukemia-derived factor/thioredoxin, produced by both human T-lymphotropic virus type I- and Epstein-Barr virus-transformed lymphocytes, acts as an autocrine growth factor and synergizes with interleukin 1 and interleukin 2. Proc. Natl. Acad. Sci. USA 87, 8282-8286 (1990).

16. Nickel, W. The mystery of nonclassical protein secretion. A current view on cargo proteins and potential export routes. Eur. J. Biochem. 270, 2109-2119 (2003).

17. Jefferey, C.J. Moonlighting proteins. Trends Biochem. Sci. 24, 8-11 (1999).

18. Chen, C. \& Okayama, H. High-efficiency transformation of mammalian cells by plasmid DNA. Mol. Cell. Biol.7, 2745-2752 (1987).

19. Altschul, S.F. et al. Gapped BLAST and PSI-BLAST: a new generation of protein database search programs. Nucleic Acids Res. 25, 3389-3402 (1997).

20. Cau E., Gradwohl G., Fode C. \& Guillemot F. Mash 1 activates a cascade of bHLH regulators in olfactory neuron progenitors. Development 124, 1611-1621 (1997).

21. Dixon, W.J. \& Massey, F.J. Jr. Statistical test for significance. Introduction to Statistical Analysis (McGraw-Hill, New York, 1969). 